\title{
METHODOLOGY OF DESIGNING THE GEOMETRY OF THE BEVEL GEAR USING NUMERICAL SIMULATION TO GENERATE THE TEETH FLANK SURFACES
}

\author{
Jadwiga PISULA*, Mieczysław PŁOCICA* \\ *Department of Mechanical Design, Rzeszow University of Technology, Al. Powstańców Warszawy 12, 35-959 Rzeszów, Poland \\ ipisula@prz.edu.pl, mplocica@prz.edu.pl
}

\begin{abstract}
The present paper describes modern methodology of the bevel gear design with a particular focus on issues concerning the theoretical basis and the preparation of the numerical simulation of the machining. The assumptions used in developing the mathematical model of cutting teeth are given and an example of the teeth flank surfaces of a gear and a pinion resulting from the virtual processing is shown. The correctness of the mathematical model of cutting teeth was verified by comparing the resulting based on the model grid points, the side of the tooth surface, resulting from the simulation cutting teeth in CAD. A high convergence of the two surface geometry was demonstrated, which allows for the use of the analysis for each of the models independently.
\end{abstract}

Key words: Bevel Gears, Gleason, Cutting Simulation

\section{INTRODUCTION}

Virtual simulations of gear members machining, and a subsequent verification of their mating in a construction pair are an inherent element in the modern design process of bevel gears. The theoretical geometry of the teeth resulting from the technological calculation process does not usually show a correct mating, considering the execution of errors of the gear (even those permitted tolerances) and assembly errors. Therefore, at the stage of making the gear and pinion, the geometry of the flank surfaces should be adjusted to a form barely sensitive to these errors. For this purpose, the geometry of toothing is modified at the stage of planning the technology as well as the calculation of parameters of cutting gears.

By moving to virtual space a number of activities which were traditionally carried out on the multi-membered-scored test gears a significant reduction in time and cost of introducing a new conic pair to the production is achieved. At the same time one can get a successful cooperation of the first physically cut pair of gears already. However, this requires a very good knowledge of one of the commercial systems of computer-aided design (and the purchase of such a system), or the creation of a suitable software tool. One possibility in this regard is to design a numerical model of machining. Properly reproduced (in the model) technological systems and cutting kinematics are the basis for verification of the mating of the pair construction and the introduction of modifications to achieve proper contact area and workflow.

\section{MATHEMATICAL PROCESSING MODEL}

For the purpose of the present study a mathematical model of the machine tool as a set of RH Cartesian coordinate systems was developed, reproducing the actual components of the machine. In the case of the processing model construction it is necessary to consider tooth flank geometry obtained by generation or forming method, where the side of the tooth is completely tangential to the surface of the tool performance. While the gear generating the tooth flank record, which is the envelope surface of the tool performance, is derived from the system of equations (1), which includes the equation of the tool performance surface family (2) and the equation of meshing determined on the basis of the kinematic theory of envelope by F. Litvin (Litvin and Fuentes, 2004; Litvin et al., 2006).

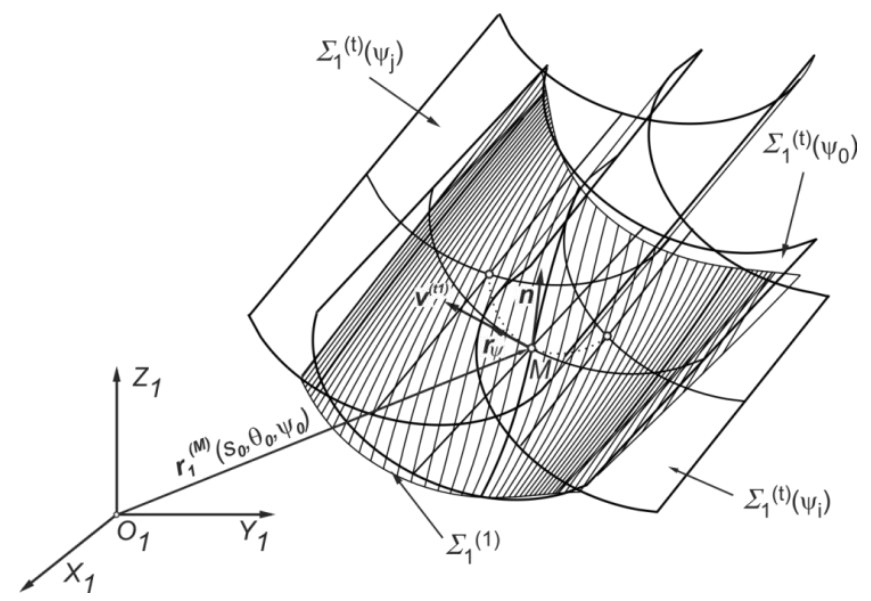

Fig. 1. Envelope $\Sigma_{1}{ }^{(1)}$ of one parametric surface family $r_{1}(s, \theta, \psi)[5]$

$$
\begin{aligned}
& \left\{\begin{array}{c}
\boldsymbol{r}_{\mathbf{1}}\left(s_{t}, \theta_{t}, \psi_{t}\right) \\
\boldsymbol{n}_{\mathbf{1}} \cdot \boldsymbol{v}_{\mathbf{1}}^{\boldsymbol{t} \mathbf{1}}\left(s_{t}, \theta_{t}, \psi_{t}\right)=0
\end{array}\right. \\
& \boldsymbol{r}_{\mathbf{1}}\left(s_{t}, \theta_{t}, \psi_{t}\right)=\boldsymbol{M}_{\mathbf{1} \boldsymbol{t}}\left(\psi_{t}\right) \cdot \boldsymbol{r}_{\boldsymbol{t}}\left(s_{t}, \theta_{t}\right)
\end{aligned}
$$

where: $\psi_{\mathrm{t}}$ - movement parameter, $\mathrm{n}_{1}$ - unitary normal vector to the tool surface specified in the system $S_{1},-v_{1}^{t 1}\left(s_{t}, \theta_{t}, \psi_{t}\right)-$ the relative tool speed in relations to the gear in the system $S_{1}$, $r_{t}\left(s_{t}, \theta_{t}\right)$ - vector equation of the surface tool performance in the system $\mathrm{S}_{1}, \mathrm{M}_{1 \mathrm{t}}\left(\psi_{\mathrm{t}}\right)$ - transformation matrix as a product of matrixes reflecting the single rotations and shifts between the systems introduced into the model of a technological gear. 
Parametric recording of the surface tool performance in the system associated with the tool $S_{t}$, is represented by equation (3), whereas the unitary normal vector to these surfaces is given by (4):

$\boldsymbol{r}_{\boldsymbol{t}}\left(s_{t}, \theta_{t}\right)=\left[\begin{array}{c}\cos \theta_{t} \cdot\left(r_{i} \pm s_{t} \sin \alpha_{i}\right) \\ \sin \theta_{t} \cdot\left(r_{i} \mp s_{t} \sin \alpha_{i}\right) \\ -s_{t} \cos \alpha_{i}\end{array}\right]$

$\boldsymbol{n}_{\boldsymbol{t}}\left(\theta_{t}\right)=\left[\begin{array}{c}-\cos \theta_{t} \cdot \cos \alpha_{i} \\ -\sin \theta_{t} \cdot \cos \alpha_{i} \\ \mp \sin \alpha_{i}\end{array}\right]$

where: $s_{t}, \theta_{t}$ - parameters associated respectively with the length of the cutting edge and the creation of a conical surface of revolution (Fig. 2); $\alpha_{i} r_{i}$, - the angle of the cutting tool profile and the radius of the tool head $i=(w k, w p)$ index " $w k$ " refers to the processing of the concave side of the tooth flank by means of outer cutting tools, index "wp" refers to the processing of the convex side of the tooth flank by means of inner cutting tool, (for the outer cutting tools there is the "upper" designation and for the inner ones the "lower" designation.
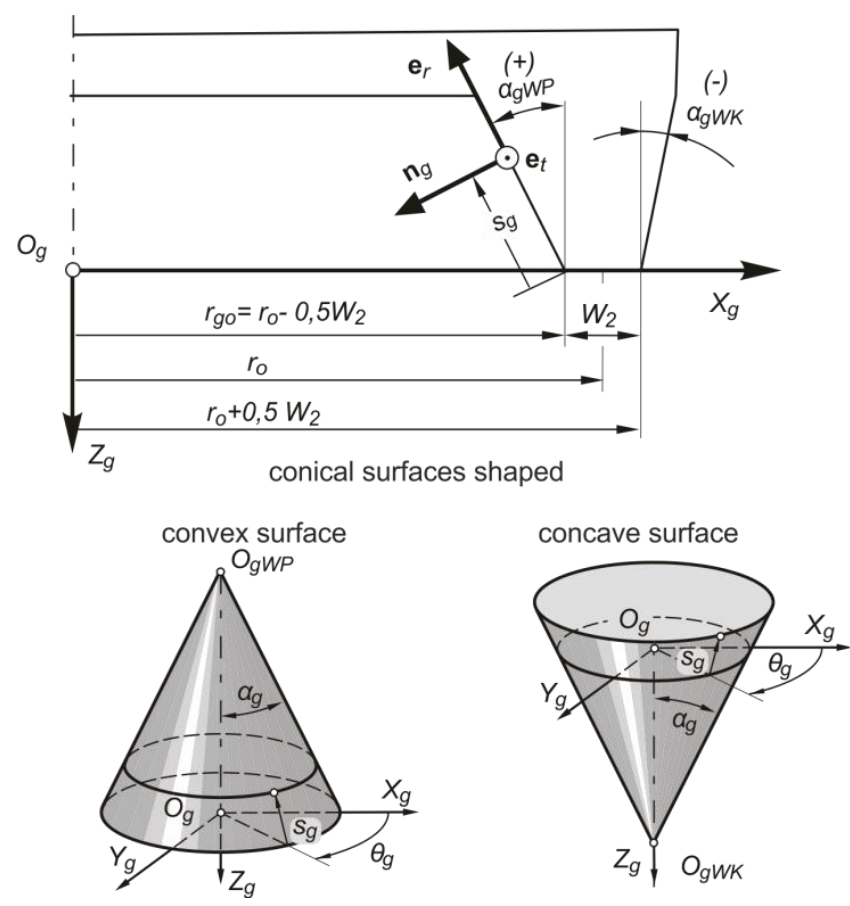

Fig. 2. Geometry of cone surfaces to cut off concave and convex tooth flank (Marciniec, 2003)

Due to the complexity of the system of coordinate modeling systems, the technological gear into which the nine parameters of base settings of the machine tool are introduced (without taking into account the geometry of the tool and the processed gear) (Fig. 3), the meshing equation cannot be solved explicitly by ousting one of the parameters (Marciniec et al., 20111; Pisula, 2006). In this case, the obtained tooth flank surface of the gear is a set of points, respectively indexed, which are the numerical solution of the system (1). The coordinates of the sought points correspond to the coordinates of the points placed on the reference grid disposed in an axial section of the cutting tooth within the active tooth height. On the obtained set of points the area is spread by the use of interpolation. Thus obtained interpolated flank tooth surface is subjected to further analysis in the mathe- matical model of construction gear (Marciniec et al., 2011; Pisula and Płocica, 2012).
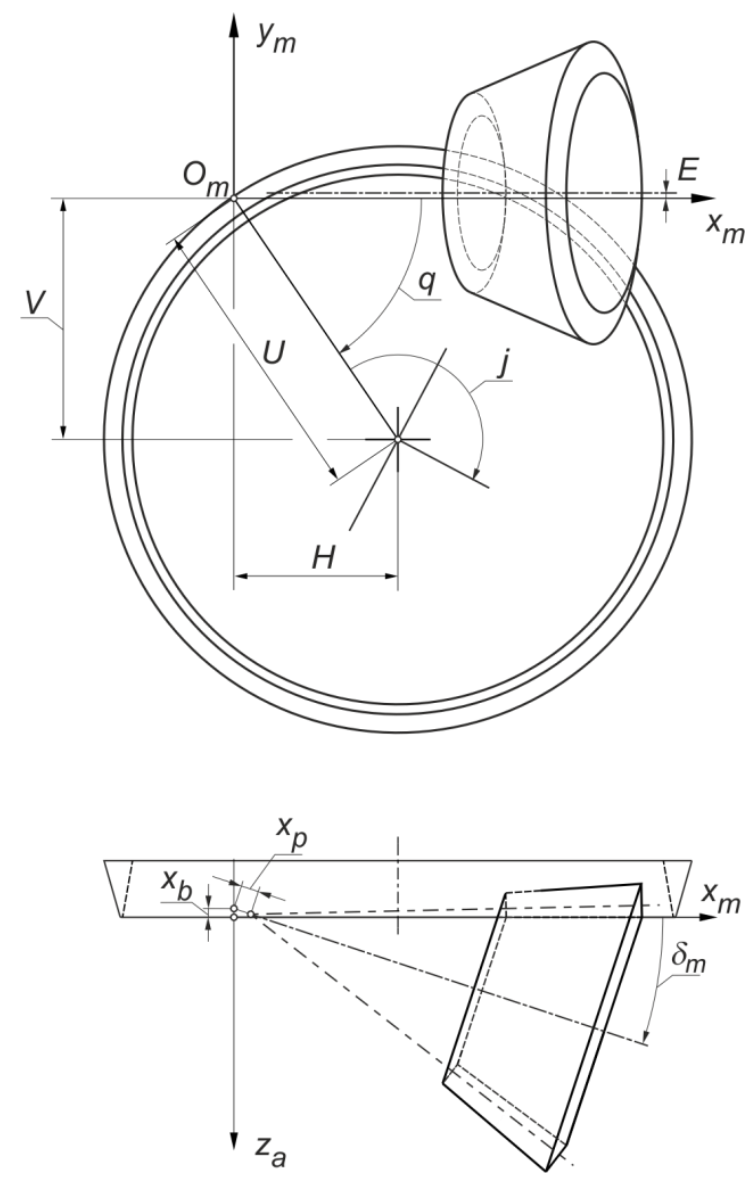

Fig. 3. Coordinate systems modeling the technological gear with parameter of base settings of the machine tool

\section{METHODOLOGY OF WORKS EXEMPLIFIED BY GLEASON GEAR OF 17/35 CUT BY SGT METHOD}

While designing Gleason bevel gear it is necessary to define the basic geometry and then complete it with the use of the dependencies included in the first tab of the calculation process. The result is a set of data for the preparation of the technology (Tab. 1). The next step is the selection of tool geometry (Tab. 2), and then determination of the basic machine settings to make a simulation of gear cutting. There should be no interference in the teeth flank surfaces of the gear $(1,2,6,10,11)$. They are used as reference surfaces, to which the pinion teeth are adapted in order to obtain the correct indicators of quality for gear pair mesh. This is due to manufacturing reasons as the pinion has a smaller number of teeth than the gear and its processing time is shorter.

Geometric and positioning data is imported into the environment in which a numerical simulation of cutting is carried out. The result is a set of points which are the numerical solution of the implemented system of equations (1) representing the gear flank surfaces and the pinion respectively. The surfaces, expressed as a mesh of points, are generated in the Mathcad and are shown in Fig. 4 (gear) and 5 (pinion). 
Tab. 1. Basic geometrical data of the gear $17 / 35$

\begin{tabular}{|l|c|l|l|}
\hline Quantity & $\begin{array}{l}\text { Desig- } \\
\text { nation }\end{array}$ & Pinion & Gear \\
\hline Number of teeth & $\mathrm{z}$ & 17 & 35 \\
\hline Hand of spiral & & Left & Right \\
\hline $\begin{array}{l}\text { External transverse } \\
\text { module }\end{array}$ & $m_{t}$ & $1.860[\mathrm{~mm}]$ & \multicolumn{2}{l|}{} \\
\hline Pressure angle & $\alpha_{0}$ & $20^{\circ}$ & \\
\hline Shaft angle & $\Sigma$ & $90^{\circ}$ & \\
\hline Spiral angle & $\beta$ & $33^{\circ} 15^{\prime}$ & $3.191[\mathrm{~mm}]$ \\
\hline Mean cone distance & $\mathrm{R}$ & $30.186[\mathrm{~mm}]$ & \\
\hline Face width & $\mathrm{b}$ & $12.00[\mathrm{~mm}]$ & \\
\hline External whole depth & $\mathrm{H}$ & $3.191[\mathrm{~mm}]$ & $1.350[\mathrm{~mm}]$ \\
\hline Clearance & $\mathrm{C}$ & $0.350[\mathrm{~mm}]$ & {$[\mathrm{mm}]$} \\
\hline $\begin{array}{l}\text { External height of tooth } \\
\text { head }\end{array}$ & $h_{a}$ & $1.837[\mathrm{~mm}]$ & 1.004 \\
\hline $\begin{array}{l}\text { External height of tooth } \\
\text { root }\end{array}$ & $h_{f}$ & $1.354[\mathrm{~mm}]$ & $2.187[\mathrm{~mm}]$ \\
\hline Pitch angle & $\delta$ & $25^{\circ} 54^{\prime} 23^{\prime \prime}$ & $64^{\circ} 5^{\prime} 37^{\prime \prime}$ \\
\hline Dedendum angle & $\theta_{f}$ & $0^{\circ} 30^{\prime} 58^{\prime \prime}$ & $0^{\circ} 50^{\prime} 2^{\prime \prime}$ \\
\hline Addendum angle & $\theta_{a}$ & $0^{\circ} 50^{\prime} 2^{\prime \prime}$ & $0^{\circ} 30^{\prime} 58^{\prime \prime}$ \\
\hline & &
\end{tabular}

Tab. 2. Geometrical tool data

\begin{tabular}{|c|l|r|r|}
\hline \multicolumn{2}{|l|}{ Tool parameters } & \multicolumn{1}{l|}{$\begin{array}{l}\text { Pinion } \\
\text { (concave) }\end{array}$} & Gear (convex) \\
\hline$D_{0}$ & $\begin{array}{l}\text { Diameter of cutter } \\
\text { head }\end{array}$ & $38.862[\mathrm{~mm}]$ & $38.100[\mathrm{~mm}]$ \\
\hline$W_{2}$ & Width of the blade tip & $0.508[\mathrm{~mm}]$ & $0.762[\mathrm{~mm}]$ \\
\hline$R_{02}$ & Fillet radius & $0.381[\mathrm{~mm}]$ & $0.381[\mathrm{~mm}]$ \\
\hline$\alpha_{w k}$ & $\begin{array}{l}\text { Cutter pressure } \\
\text { angle (outer) }\end{array}$ & $20\left[^{\circ}\right]$ & $20\left[^{\circ}\right]$ \\
\hline$\alpha_{w p}$ & $\begin{array}{l}\text { Cutter pressure } \\
\text { angle (inner) }\end{array}$ & $20\left[^{\circ}\right]$ & $20\left[^{\circ}\right]$ \\
\hline
\end{tabular}

Tab. 3. The basic setting data for the gear and the pinion processing

\begin{tabular}{|l|r|r|}
\hline \multicolumn{1}{|c|}{$\begin{array}{c}\text { The basic machine } \\
\text { setting }\end{array}$} & pinion (concave) & gear (convex) \\
\hline Cradle angle q & $43^{\circ} 54^{\prime}$ & $38^{\circ} 54^{\prime}$ \\
\hline Radial distance $\mathrm{U}$ & $25,538[\mathrm{~mm}]$ & $25,368[\mathrm{~mm}]$ \\
\hline Hypoid offset $\mathrm{E}$ & $0,212[\mathrm{~mm}]$ & $0[\mathrm{~mm}]$ \\
\hline Machine root angle $\delta_{\mathrm{m}}$ & $25^{\circ} 23^{\prime}$ & $63^{\circ} 15^{\prime}$ \\
\hline Machine center to back xp & $-0,156[\mathrm{~mm}]$ & $0[\mathrm{~mm}]$ \\
\hline Sliding base $\mathrm{xb}$ & $-1,213[\mathrm{~mm}]$ & $-1.660[\mathrm{~mm}]$ \\
\hline Tilt angle i & $0^{\circ} 44^{\prime}$ & $0\left[^{\circ}\right]$ \\
\hline Swivel angle j & $10^{\circ} 15^{\prime}$ & $0\left[^{\circ}\right]$ \\
\hline Roll ratio & 0.436922 & 0.899604 \\
\hline
\end{tabular}

The obtained surfaces are used for further analyses in the mathematical model of construction gear. In case of the lack of acceptance of the results of the surface meshing, the procedure assumes the return to the selection of the base settings of individual members of the gear.

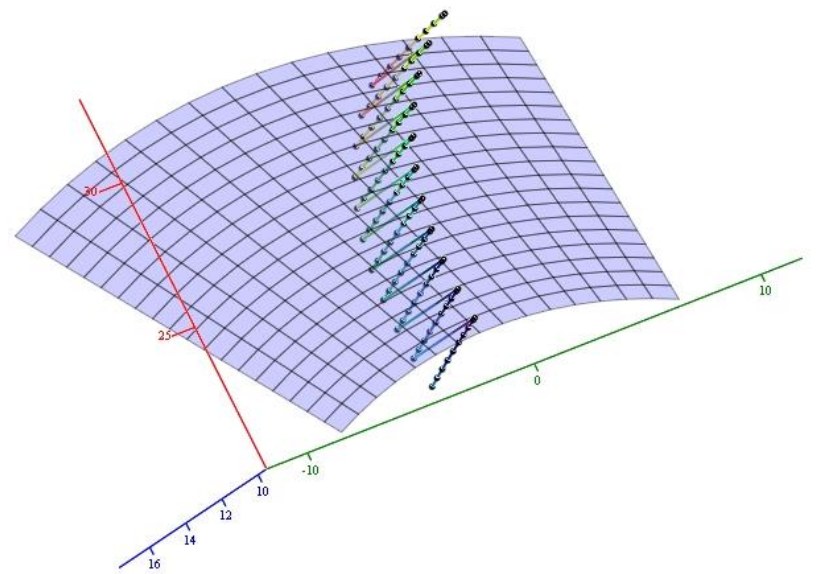

Fig. 4. The set of points representing the tooth flank surface of gear (convex)

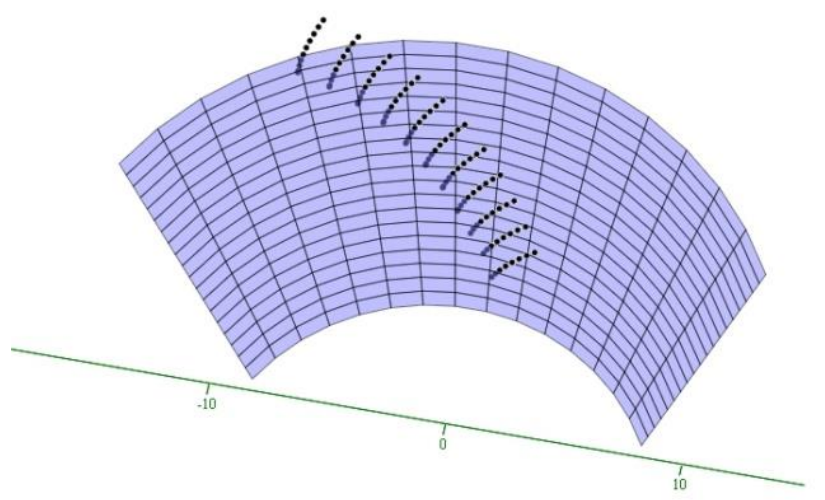

Fig. 5. The set of points representing the tooth flank surface of pinion (concave)

\section{CONCLUSIONS}

Surfaces obtained numerically were verified by comparing them with the surfaces obtained by the simulation of the direct cutting of solid models in CAD (Autodesk Inventor). The verification showed the convergence of the results (Fig. 6). The superimposition of the surface spread on the grid points of whose coordinates were obtained as a numerical solution of the equations (1) on the lateral surface of the CAD model obtained in Marciniec and Sobolewski (2010) shows slight differences in the tooth root. Tab. 4 shows the distances from the points obtained from the mathematical model, measured in the direction normal to the surface resulting from the cutting simulation in a CAD environment. The method of virtual cutting notch for the analyzed case was performed in 100 steps of iteration. Because the surface obtained from the simulation of cutting in CAD is a collection of microsurfaces, simple vectors containing the normal to the surface and passing through certain points of the grid can find the edges microsurfaces or penetrate the interior. Depending upon the case, the distance measured from the point of mesh to pierce point is different, namely on the edge it is close to zero, in the second case this distance is greater. The measured value shows the distance of no more than hundredths of microns (shown in the analyzed gear max. Deviation of $0.061 \mathrm{um}$ ). 
Tab. 4. Distances (given in microns) between the points obtained from the mathematical model, and the surface obtained from the CAD simulation

\begin{tabular}{|c|c|c|c|c|c|c|c|c|c|c|c|}
\cline { 2 - 12 } \multicolumn{1}{c|}{} & 1 & 2 & 3 & 4 & 5 & 6 & 7 & 8 & 9 & 10 & 11 \\
\hline 1 & 0.015 & 0.0001 & 0.005 & 0.001 & 0.027 & 0.027 & 0.0001 & 0.009 & 0.033 & 0.029 & 0.001 \\
\hline 2 & 0.009 & 0.013 & 0.0001 & 0.0001 & 0.02 & 0.02 & 0.033 & 0.031 & 0.032 & 0.034 & 0.034 \\
\hline 3 & 0.007 & 0.009 & 0.021 & 0.065 & 0.044 & 0.044 & 0.03 & 0.004 & 0.001 & 0.024 & 0.017 \\
\hline 4 & 0.014 & 0.018 & 0.007 & 0.025 & 0.027 & 0.027 & 0.034 & 0.035 & 0.001 & 0.027 & 0.033 \\
\hline 5 & 0.006 & 0.021 & 0.016 & 0.008 & 0.023 & 0.023 & 0.026 & 0.042 & 0.01 & 0.013 & 0.033 \\
\hline 6 & 0.021 & 0.012 & 0.034 & 0.026 & 0.026 & 0.026 & 0.002 & 0.0001 & 0.033 & 0.0001 & 0.061 \\
\hline 7 & 0.022 & 0.022 & 0.02 & 0.039 & 0.009 & 0.009 & 0.02 & 0.012 & 0.023 & 0.009 & 0.058 \\
\hline 8 & 0.0001 & 0.002 & 0.012 & 0.01 & 0.0001 & 0.0001 & 0.021 & 0.026 & 0.026 & 0.034 & 0.001 \\
\hline 9 & 0.0001 & 0.021 & 0.012 & 0.02 & 0.004 & 0.004 & 0.027 & 0.032 & 0.033 & 0.029 & 0.007 \\
\hline 10 & 0.021 & 0.017 & 0.024 & 0.016 & 0.008 & 0.008 & 0.006 & 0.032 & 0.013 & 0.022 & 0.035 \\
\hline
\end{tabular}

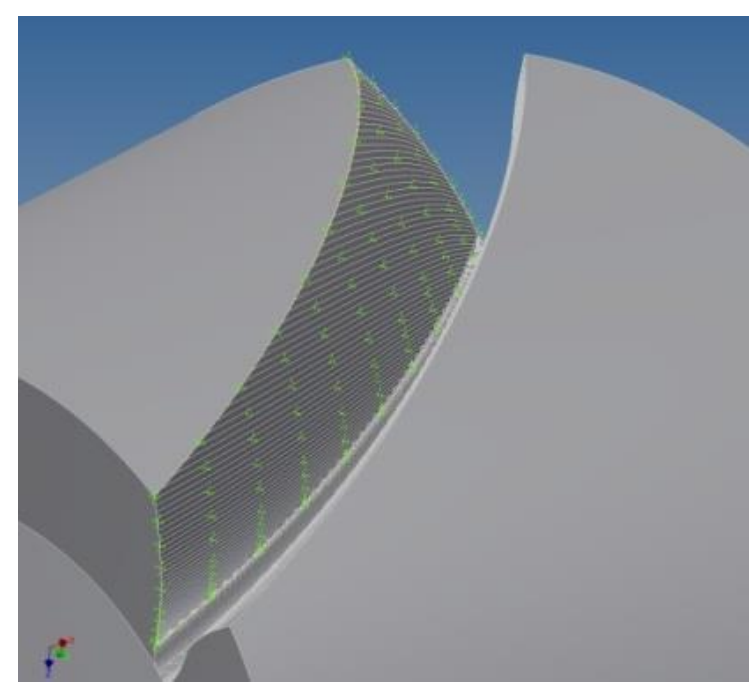

Fig. 6. Comparison of numerical and CAD convex surface of pinion

The results of verification adequately support the accuracy of the mathematical technological model and the numerical simulation of the direct cutting of solid models in CAD. This proves that the developed methodology of numerical processing is reliable and can be used in the process bevel gears design.

\section{REFERENCES}

1. Artoni A., Gabiccini M., Guiggiani M., (2008), Nonlinear identification of machine settings for flank form modifications in hypoid gears, Journal of Mechanical Design, 130 (2008), 112602.
2. Gabiccini M., Artoni A., Guiggiani M., (2012), On the identification of machine settings for gear surface topography corrections, Journal of Mechanical Design 133, 041004 (1-8).

3. Litvin F. L., Fuentes A. (2004), Gear geometry and applied theory, Cambridge Univ Pr.

4. Litvin F. L., Fuentes A., Hayasaka K. (2006), Design, manufacture, stress analysis, and experimental tests of low-noisehigh endurance spiral bevel gears, Mechanism and Machine Theory, 41, 83-118.

5. Marciniec A. (2003), Synthesis and analysis of meshing for spiral bevel gears, Publishing House of Rzeszow University of Technology, Rzeszow (in Polish).

6. Marciniec A., Sobolewski B. (2010), Simulation of spiral bevel gear cutting process in environment of Inventor 2010, Engineering Forum ProCAx, Sosnowiec-Siewierz (in Polish).

7. Marciniec A., Pisula J., Płocica M., Sobolewski B. (2011), Design of bevel gears using mathematical modeling and simulation in the CAD environment, Mechanik, 7, 602-605 (in Polish).

8. Pisula J.; Płocica M. (2012), Analysis of meshing of bevel gears on the basis of a mathematical model of machining processes and direct simulation of cutting in Inventor, Mechanik, 1, 78-79 (in Polish).

9. Pisula J. (2006), Mathematical model of geometry and meshing of generating cylindrical gear teeth, Doctoral thesis, Rzeszow (in Polish).

10. Simon V. (2008), Machine-Tool Settings to Reduce the Sensitivity of Spiral Bevel Gears to Tooth Errors and Misalignments, ASME Journal of Mechanical Design, 130(8), 082603, 1-10.

11. Sinh Y. (2010), A novel ease-off flank modification methodology for spiral bevel and hypoid gears, Mechanism and Machine Theory $45,1108-1124$

Research carried out in the framework of the Project "Modern materia technologies applied in the aerospace industry", No. POIG.01.01.02-00015/08-00 in the Operational Programme of Innovative Economy (OPIE). Project co-financed by the European Union through the European Regional Development Fund. 